\title{
Pin1 modulates RNA polymerase II activity during the transcription cycle
}

\author{
Yu-Xin Xu and James L. Manley ${ }^{1}$ \\ Department of Biological Sciences, Columbia University, New York, New York 10027, USA
}

The C-terminal domain of the RNA polymerase (RNAP) II largest subunit (CTD) plays a critical role in coordinating multiple events in pre-mRNA transcription and processing. Previously we reported that the peptidyl prolyl isomerase Pin1 modulates RNAP II function during the cell cycle. Here we provide evidence that Pin1 affects multiple aspects of RNAP II function via its regulation of CTD phosphorylation. Using chromatin immunoprecipitation (ChIP) assays with CTD phospho-specific antibodies, we confirm that RNAP II displays a dynamic association with specific genes during the cell cycle, preferentially associating with transcribed genes in $\mathrm{S}$ phase, while disassociating in $M$ phase in a matter that correlates with changes in CTD phosphorylation. Using inducible Pin1 cell lines, we show that Pin1 overexpression is sufficient to release RNAP II from chromatin, which then accumulates in a hyperphosphorylated form in nuclear speckle-associated structures. In vitro transcription assays show that Pin1 inhibits transcription in nuclear extract, while an inactive Pin1 mutant in fact stimulates it. Several assays indicate that the inhibition largely reflects Pin1 activity during transcription initiation and not elongation, suggesting that Pin1 modulates CTD phosphorylation, and RNAP II activity, during an early stage of the transcription cycle.

[Keywords: CTD; CTD phosphorylation; Pin1; prolyl isomerase; RNAP II]

Supplemental material is available at http://www.genesdev.org.

Received July 13, 2007; revised version accepted September 19, 2007.

The C-terminal domain of the RNA polymerase (RNAP) II largest subunit (CTD) is a unique structural domain, consisting of up to 52 tandem repeats of the heptapeptide consensus sequence YSPTSPS. This domain is essential for viability and plays a vital role in gene expression. It has been shown to be important for transcription and critical for many subsequent cotranscriptional events, including capping, splicing, and polyadenylation of the pre-mRNA, and lately, chromatin remodeling and DNA repair (Hirose and Manley 2000; Maniatis and Reed 2002. Sims et al. 2004; Meinhart et al. 2005).

Phosphorylation of the CTD is known to play a crucial role in regulating RNAP II activities. The CTD has multiple phosphorylation sites, but phosphorylation occurs predominantly on Ser 2 and Ser 5 of the heptad repeats (Dahmus 1996). Typically, RNAP II participates in formation of the preinitiation complex (PIC) in its unphosphorylated form, RNAP IIA (Laybourn and Dahmus 1989; Lu et al. 1991). The CTD is required for stable PIC formation by interacting with the Mediator complex (Myers and Kornberg 2000). The transition from initiation to fully elongating RNAP II involves multiple steps. The release of RNAP II from the PIC coincides with CTD phosphorylation at Ser 5 by CDK7, the kinase sub-

${ }^{1}$ Corresponding author.

E-MAIL jlm2@columbia.edu; FAX (212) 865-8246.

Article is online at http://www.genesdev.org/cgi/doi/10.1101/gad.1592807. unit of TFIIH (McCracken et al. 1997; Komarnitsky et al. 2000; Schroeder et al. 2000). The phosphorylated CTD facilitates promoter clearance by disassociating from the Mediator and subsequently recruits the capping machinery for the pre-mRNA $5^{\prime}$ capping reaction. Ser 5 phosphorylation diminishes as RNAP II moves into the coding region (Komarnitsky et al. 2000), presumably reflecting dephosphorylation by the CTD phosphatase FCP1 (Cho et al. 2001).

Transcription elongation is controlled by multiple factors. At the initial stage, RNAP II is repressed by negative elongation factors. For instance, DSIF and NELF cooperate to inhibit elongation of RNAP II by increasing the duration time at promoter-proximal pause sites (Wada et al. 1998; Yamaguchi et al. 1999). This repression can be relieved by the positive elongation factor pTEFb, a complex containing CDK9 kinase and one of several cyclin subunits (Price 2000). CDK9 phosphorylates several subunits of DSIF and NELF (Yamada et al. 2006), as well as Ser 2 of the CTD, to generate a productive RNAP II elongation complex (Ni et al. 2004). In contrast to Ser 5, Ser 2 phosphorylation persists throughout the coding region and $3^{\prime}$ end of the gene, and Ser 2 phosphorylated CTD is believed to stimulate RNA 3' processing (Cho et al. 2001; Ahn et al. 2004; Ni et al. 2004). After or at termination, the CTD is presumably dephosphorylated to be recycled for the next round of transcription (Cho et al. 1999). 
All the above cotranscriptional events require a large number of protein factors, which are coordinately recruited by the CTD. This requires a flexible and dynamic structure, which should be subject to regulation during the transcription process. The structural flexibility of the CTD was revealed by the three-dimensional structure of yeast RNAP II, in which the extended CTD is directly adjacent to the exit groove of nascent pre-mRNA via a lengthy and mobile linker (Cramer et al. 2001). The dynamic nature of the CTD is supported by recent structural studies of CTD peptides with interacting proteins, including the capping enzyme Cgt 1 , human prolyl isomerase Pin1, and the 3 '-RNA processing factor Pcf11 (Meinhart et al. 2005). Comparison of these structures revealed that the CTD adopts different conformational states for its different binding targets, with various preferences for CTD phosphorylation status. The capping enzyme shows a strong preference for Ser 5 phosphorylation (Fabrega et al. 2003) and Pcf11 shows a strong preference for Ser 2 phosphorylation (Meinhart and Cramer 2004), whereas Pin1 shows equal affinity to both (Verdecia et al. 2000). The structure of the CTD in its unphosphorylated form seems relatively compact (Meredith et al. 1996). However, phosphorylation appears to result in an extended CTD structure, which is more sensitive to protease digestion (Laybourn and Dahmus 1989; Zhang and Corden 1991). These findings suggest that phosphorylation of the CTD not only affects its conformation state, but also generates distinct recognition interfaces for binding interacting proteins.

The CTD is proline rich, and this residue directly participates in the interface between the CTD and interacting proteins. A characteristic of the prolyl peptide bond is a slow rate of cis/trans isomerization (Fisher 1994). This could be a rate-limiting step for CTD conformational changes upon phosphorylation, suggesting the involvement of a prolyl isomerase. Of the known prolyl isomerases, Pin 1 is the only one that is phosphorylation dependent, with a binding motif of phosphorylated serine or threonine followed by proline (pS/pT-P) (Yaffe et al. 1997). The CTD is thus an optimal target for Pin 1 simply because of the multiple potential binding sites. Pin 1 indeed interacts with phosphorylated RNAP IIO (Albert et al. 1999; Wu et al. 2000) and is involved in some aspect of pre-mRNA $3^{\prime}$ end processing in yeast (Hani et al. 1999; Morris et al. 1999). Pin1 can in fact influence the structure and function of RNAP II by modulating CTD phosphorylation (Xu et al. 2003). Pin1 inhibits dephosphorylation of RNAP II by the CTD phosphatase FCP1 and favors phosphorylation by CTD kinases, such as cdc2/cyclin B (Xu et al. 2003; Palancade et al. 2004). Overexpression of Pin 1 induces hyperphosphorylation of RNAP II, which in turn reduces RNAP II activities both in transcription and in pre-mRNA splicing. Consistent with this, a highly phosphorylated, Pin1dependent RNAP II isoform, called RNAP IIOO, was found in M-phase cells (Xu et al. 2003).

Here we describe experiments that provide further insight into the roles played by Pin 1 in modulating RNAP II transcription. Using chromatin immunoprecipitation
(ChIP) assays, we first show that differentially phosphorylated forms of RNAP II associate with active genes in distinct ways throughout the cell cycle. Importantly, inducible overexpression of Pin1 leads to dissociation of RNAP II from genes and accumulation of the hyperphosphorylated forms in speckle-related structures in the nucleus. Extending these results, addition of wild-type Pin1 to nuclear extract (NE) inhibits RNAP II but not RNAP III transcription, while addition of a dominantnegative Pin 1 mutant, or depletion of endogenous Pin1, enhances transcription. Several lines of evidence indicate that the Pin1-induced inhibition of transcription occurs during the transition from initiation to elongation, and not during actual elongation. Together, our data indicate that Pin 1 modulates RNAP II activity in both the transcription cycle and the cell cycle.

\section{Results}

Variable association of RNAP II isoforms with active genes during the cell cycle

Our previous studies showed that Pin 1 regulates RNAP II activities by influencing the phosphorylation status of the CTD. We also provided evidence that RNAP II displays dynamic phosphorylation changes during cell cycle progression-specifically, RNAP IIO accumulates in S phase and the more highly phosphorylated IIOO isoform in $M$ phase as detected by Western analyses-and that Pin 1 is required for the formation of RNAP IIOO (Xu et al. 2003). To investigate this further, we first performed ChIP assays to examine how CTD phosphorylation status correlates with the presence of RNAP II along active genes throughout the cell cycle. To this end, HeLa cells were synchronized at the boundary of G1/S phases with a double thymidine block, released into the cell cycle, and harvested every $2 \mathrm{~h}$ (see Materials and Methods for details). Cross-linked cell extracts were used for ChIP assays first with an antibody specific for RNAP II phosphorylated at Ser 5 (H14), and DNA products were amplified by PCR with primers for the promoter, coding, and poly $(\mathrm{A})$ regions of the $\beta$-actin gene (Fig. 1A). Consistent with previous studies (Komarnitsky et al. 2000; Schroeder et al. 2000), Ser 5 phosphorylation was detected mainly at the promoter region, and phosphorylation diminished in the coding and poly(A) regions. The cell cycle profiles show that Ser 5-phosphorylated RNAP II was present mainly during G1/S phase (0-6 h), significantly decreased in G2/M (8-12 h) ( 1.6-fold decrease), and was barely detectable in nocodazole-treated cells ( 5.5 -fold decrease) (12 and $14 \mathrm{~h}, \mathrm{~N}+$ ).

The same extracts were also used for ChIP assays with an antibody specific for Ser 2-phosphorylated RNAP II (H5) (Fig. 1B). In contrast to the Ser 5 phosphorylated form, Ser 2-phosphorylated RNAP II was not present at the promoter but accumulated in the coding and poly(A) regions, also consistent with previous work (Komarnitsky et al. 2000). The cell cycle profile for the Ser 2-phosphorylated isoform was, however, similar to the Ser 5 pattern, with strong signals observed in G1/S but 
A

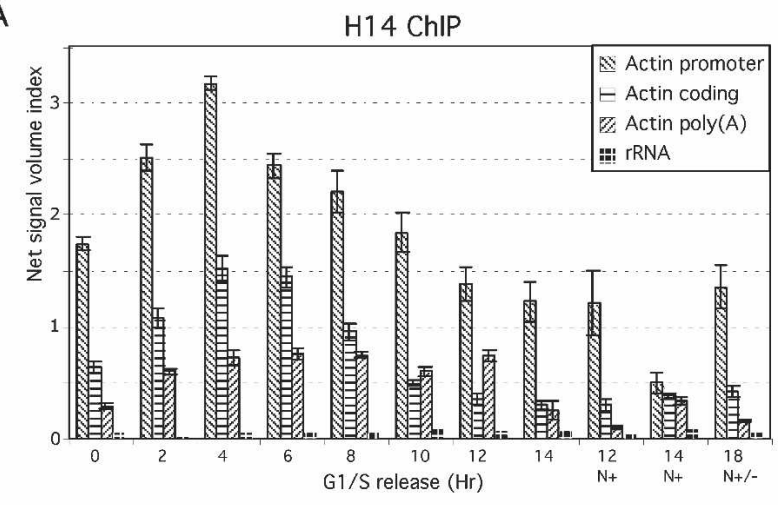

B

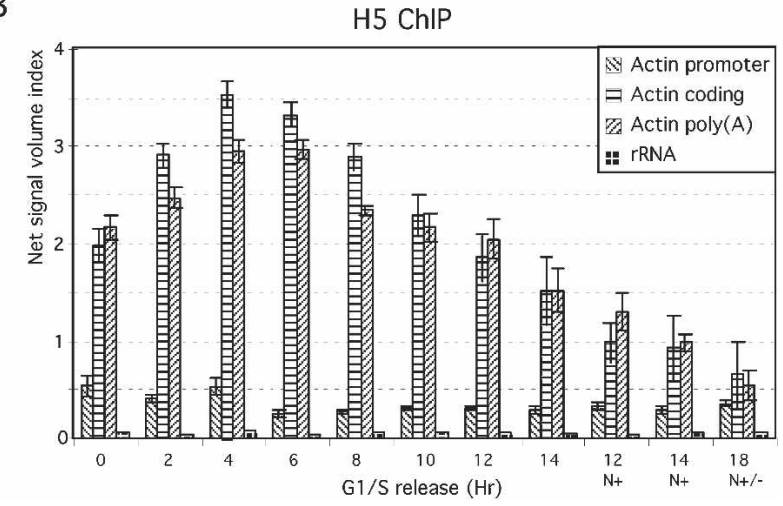

Figure 1. Association of RNAP II with active genes during the cell cycle. $(A)$ Extracts were prepared from cells released from G1/S-phase-arrested HeLa cells. ChIP experiments were performed with anti-RNAP II H14 antibody, and products were amplified with primers for the $\beta$-actin gene at the promoter, coding, and poly(A) regions and with primers for a $28 \mathrm{~S}$ rRNA gene. Quantitative data were obtained by subtracting the values of each PCR product from the signal of mock antibody with anti-mouse IgM. Standard errors were calculated from at least three independent experiments. $(B)$ ChIP experiments were performed as in $A$ but with anti-RNAP II H5 antibody, and the products were amplified with primers for the $\beta$-actin gene at the promoter, coding, and poly(A) regions and with primers for a $28 \mathrm{~S}$ rRNA gene.

not G2/M phase. (The signals in G1/S are $\sim 3.8$ and $\sim 3.4$ times stronger than those in mitotic cells for $\beta$-actin and cyclin D1 genes, respectively [Fig. 1B].) Essentially identical results were observed with a second gene, encoding cyclin D1 (data not shown). The specificity of the ChIP assays was verified with primers for the 28S rRNA gene, which revealed only very weak signals (Fig. 1A,B).

\section{Pin1 overexpression induces release of RNAP II from active genes}

We showed previously that Pin 1 is able to modulate CTD phosphorylation in vitro and in vivo. For example, inducible overexpression of Pin 1 resulted in enhanced RNAP II phosphorylation of both Ser 2 and Ser 5, giving rise to the hyperphosphorylated RNAP IIOO isoform (Xu et al. 2003). We next used this Pin 1 inducible expression approach together with RNAP II ChIP assays to examine whether modulating CTD phosphorylation by Pin1 overexpression might alter the interaction of RNAP II with active genes. Two stable cell lines containing flu-tagged wild-type or an inactive mutant Pin1 (R68,69A) were used (Xu et al. 2003). Expression of exogenous Pin1 was induced by addition of doxycycline at different time points, and total cell lysates were probed with antiPin1 antibodies to determine Pin1 expression levels (Fig. 2A,B, bottoms). RNAP II phosphorylation was also detected by Western blotting with the H14 antibody. The results indicate that inducible wild-type Pin1 expression induced overphosphorylation of RNAP II in a Pin1 dose-dependent manner (Fig. 2A, bottom), but no significant phosphorylation change was observed with the mutant Pin1 (Fig. 2B, bottom).

To examine the interaction of RNAP II with transcribing genes under conditions of Pin1 overexpression, extracts were prepared from these cell lines at various doxycycline induction times and used for ChIP with H5 and H14 antibodies. Isolated DNA was amplified by PCR with primers from the $\beta$-actin gene promoter and coding regions for H14, or both $\beta$-actin and cyclin D1 gene coding regions for H5 (Fig. 2A, top). Significantly, inducible expression of wild-type Pin 1 markedly reduced the interaction of RNAP II with both genes, at the promoter and coding regions (Fig. 2A, top), whereas mutant Pin1 expression had no effect (Fig. 2B, top). This was observed with both Ser 2 (H5) and Ser 5 (H14) phosphorylated RNAP II. Our data thus indicate a direct correlation between Pin1 levels, RNAP II CTD phosphorylation, and transcriptional activity. These results support the idea that the elevated Pin1 activity found in M-phase cells (Shen et al. 1998; Lu et al. 2002) contributes to mitotic transcriptional silencing.

\section{Pin1 modulates RNAP II phosphorylation and localization in vivo}

RNAP II is stored in 100-200 sites in the nucleoplasm (Zeng et al. 1997). This stored RNAP II is phosphorylated at Ser 2 and Ser 5, and presumably transcriptionally inactive (Bregman et al. 1995). The ability of Pin1 to modulate CTD phosphorylation suggests that Pin 1 might be able to alter the intranuclear distribution of RNAP II. To test this, and also to verify by an independent method that Pin1 enhances CTD phosphorylation, we used the inducible Pin1 cells lines to monitor CTD phosphorylation and the intranuclear distribution of RNAP II in situ. The wild-type and R68,69A mutant Pin1 cell lines described above were grown with or without doxycycline for $12 \mathrm{~h}$, and cells were then fixed, stained with anti-Pin 1 and -RNAP II antibodies, and observed by confocal microscopy. In cells without induction, the majority of Pin1 was localized in the nucleus, and Ser 2-phosphorylated RNAP II (H5) was normally distributed in a granular pattern across the entire nucleus (Fig. 3A, left). No significant difference was observed in Pin1 levels or RNAP II phosphorylation between the wild-type and 
A
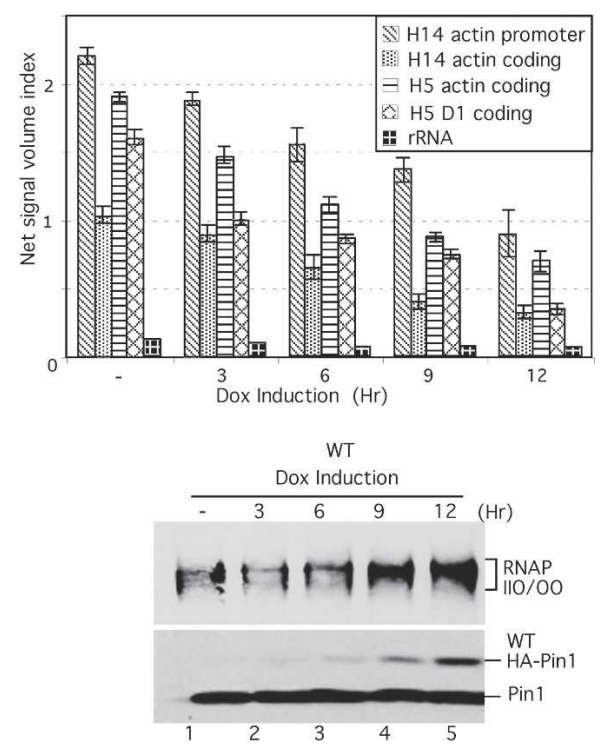

B
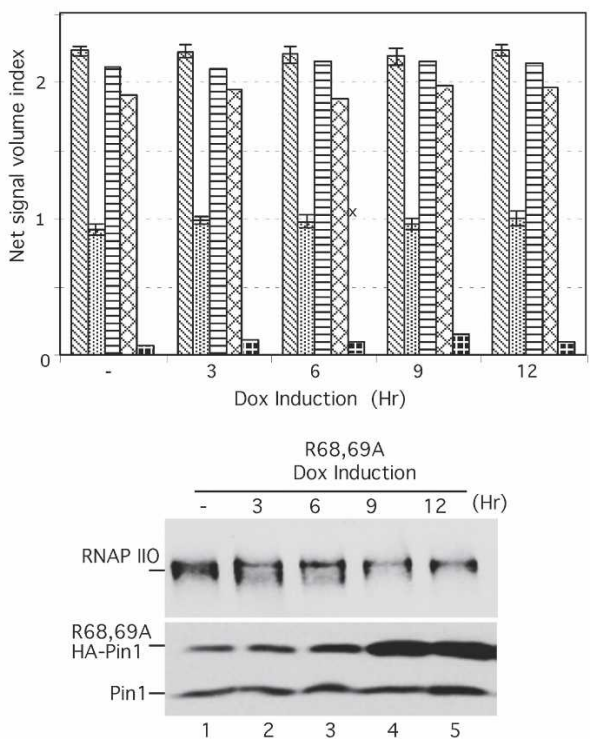

Figure 2. Pin1-induced overphosphorylation disassociates RNAP II from transcribed genes. (A) HeLa ChIP extracts were prepared from stable cell lines expressing inducible flu-tagged wild-type Pin1 in the absence (lane 1) or presence (lanes 2-5) of doxycycline (1 $\mu \mathrm{g} / \mathrm{mL}$ ) at the times indicated. ChIP experiments were performed with RNAP II H5 and H14 antibodies, and the products were amplified for the $\beta$-actin gene at the promoter and coding regions for H14, and $\beta$-actin, cyclin D1, and 28S rRNA genes at the coding regions for H5. Quantitative results were obtained as in Figure 1. (B) Similar experiments as in $A$ but with the R68,69A mutant Pin1 cell line.

mutant Pin1 cell lines. Similar results were obtained with H14 antibodies (Fig. 3A, right).

Strikingly different results were observed when Pin1 was overexpressed. As expected, treatment with doxycycline increased Pin1 expression, which accumulated predominantly in the nucleus, but was also detected in the cytoplasm (Fig. 3B). Significantly, overexpression of wild-type Pin1 greatly increased accumulation of RNAP II phosphorylated at both Ser 2 and Ser 5 (Fig. 3B, left panel, top and bottom, respectively). In contrast, in cells that had lost the ability to induce Pin1 expression (such cells accumulate with passage; data not shown), RNAP II phosphorylation was unchanged. Overexpression of mutant Pin1 did not induce overphosphorylation of RNAP II, although the expression level of mutant Pin1 was equivalent to wild type (Fig. 3B, right panel). The enhanced accumulation of phosphorylated RNAP II was not due to increased RNAP II levels since staining with 8WG16 and N20 anti-RNAP II antibodies (both of which detect nonphosphorylated epitopes) revealed similar patterns between Pin1-overexpressing and uninduced cells (Fig. 3C; data not shown).

Notably, the overphosphorylated RNAP II induced by wild-type Pin1 accumulated in enlarged dot- or specklelike structures (Fig. 3D). To investigate whether these structures correspond to nuclear speckles, which are known storage sites for mRNA processing and transcription factors (Lamond and Spector 2003), we stained wildtype Pin1-overexpressing cells with anti-SC35, which recognizes splicing factor SC35, a prototypical speckle component, and H14 antibodies. Significantly, overex- pression of wild-type Pin 1 induced the appearance of enlarged SC35-containing speckle domains (Fig. 3E, top left panel). However, the predominant structures containing the hyperphosphorylated RNAP II did not correspond to speckles (Fig. 3E, right panel). Similar results were obtained with H5 antibodies (data not shown). Together, our data confirm that elevated Pin 1 activity increases CTD phosphorylation in vivo, leading to inactivation and relocalization of RNAP II to distinct sites within the nucleus.

Pin1 interacts with S-phase-specific RNAP IIO and with $S$-phase-transcribing genes

We next wished to determine whether Pin1 has the potential to influence transcription during $S$ phase. Our previous study showed that Pin 1 can associate with the hyperphosphorylated RNAP IIOO during M phase (Xu et al. 2003). To investigate whether Pin 1 also interacts with RNAP II in S phase, we first performed coimmunoprecipitation (co-IP) experiments with Pin1-specific antibodies using S-phase NE. HeLa cells were arrested at G1/S phase and released as described above, and NEs were prepared every $2 \mathrm{~h}$ (see Supplementary Fig. 1B for cell cycle profile). The results (Fig. 4A, bottom) indicate that, as expected, Pin 1 interacted with the highly phosphorylated RNAP IIOO from mitotic extract (Fig. 4A, lane 7). There was no detectable interaction between RNAP II and Pin 1 in cells arrested in G1/S phase (Fig. 4A, lane 8), and RNAP II was detected primarily in its unphosphorylated IIA isoform (Fig. 4A, lane 1). However, 

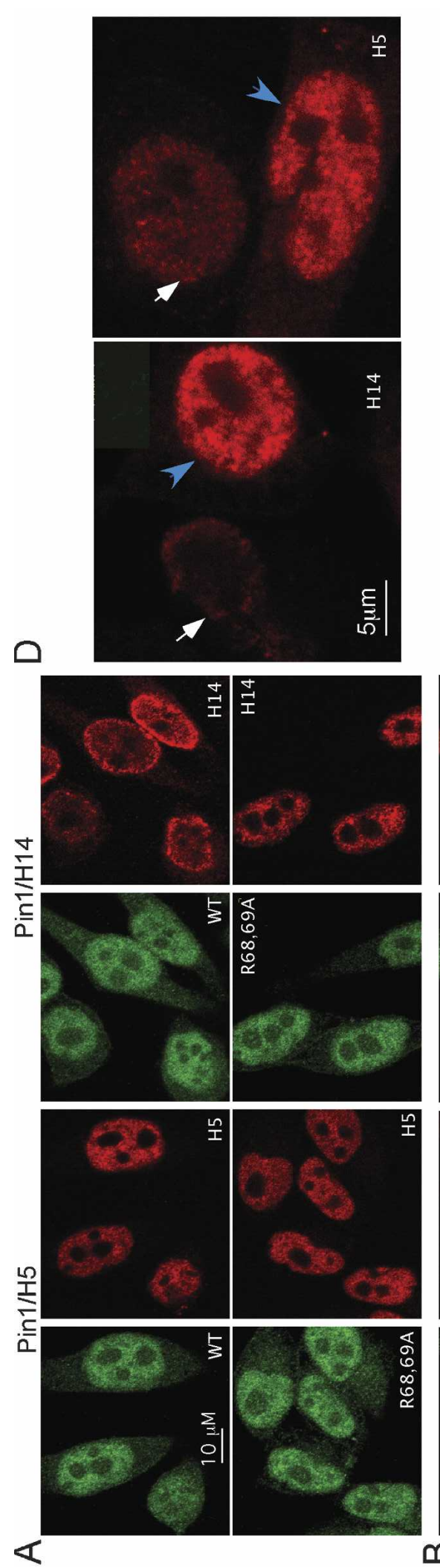

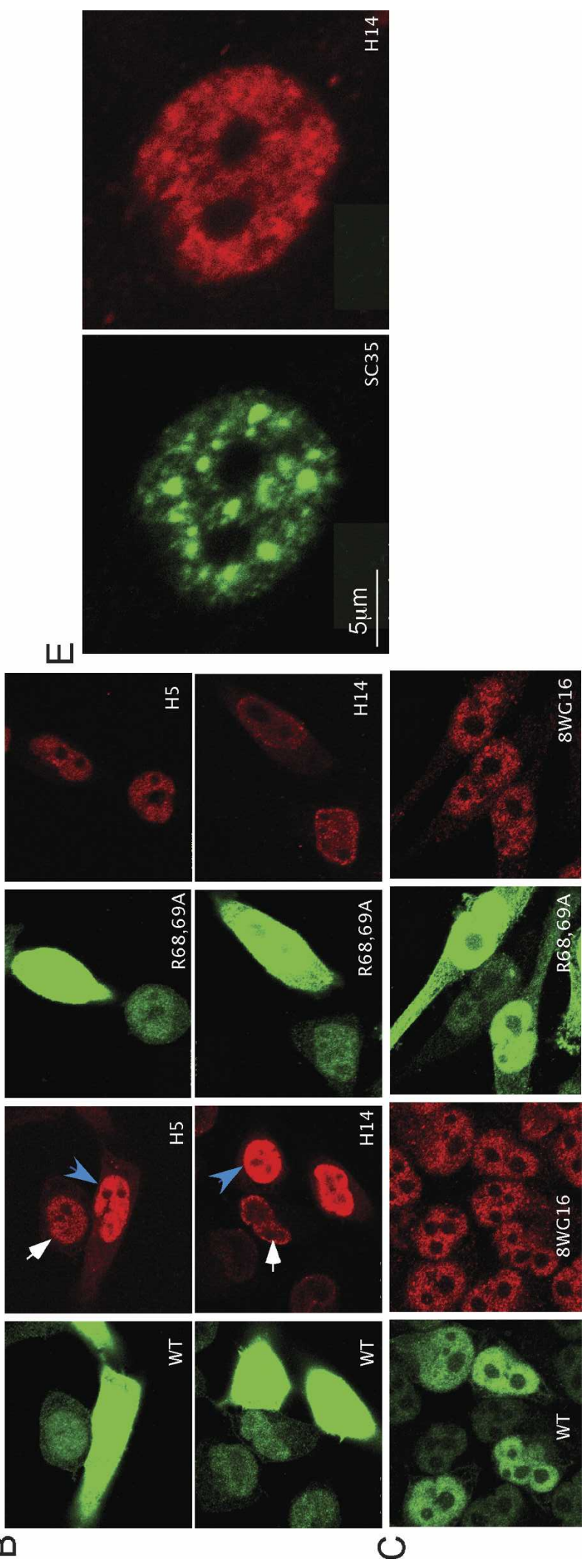

㟧曰허

के

需昰

空通

跣

ల్ల

司

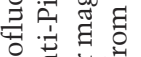

寻宁

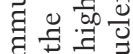

$\exists \simeq$

互营兽总

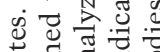

क $\cdot \exists . \Xi$

पे के चै

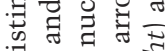

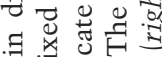

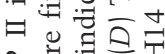

यें

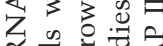

州完艺

过苛

完

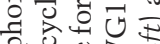

के

숭

넝에

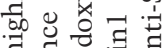

등

पे

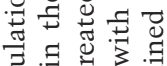

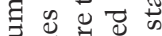

记寻寻

$\because=0$ क क

.

䓵吉艺司

¿ $\bar{\square} \Xi \Xi$

च ฐี

$\exists \approx$ ज

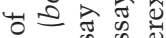

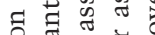

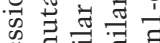

仓 近的的

잉

वे च्ठ

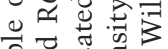

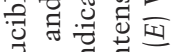

苂

$\dot{0}$ \&

๑

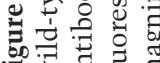

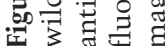


A
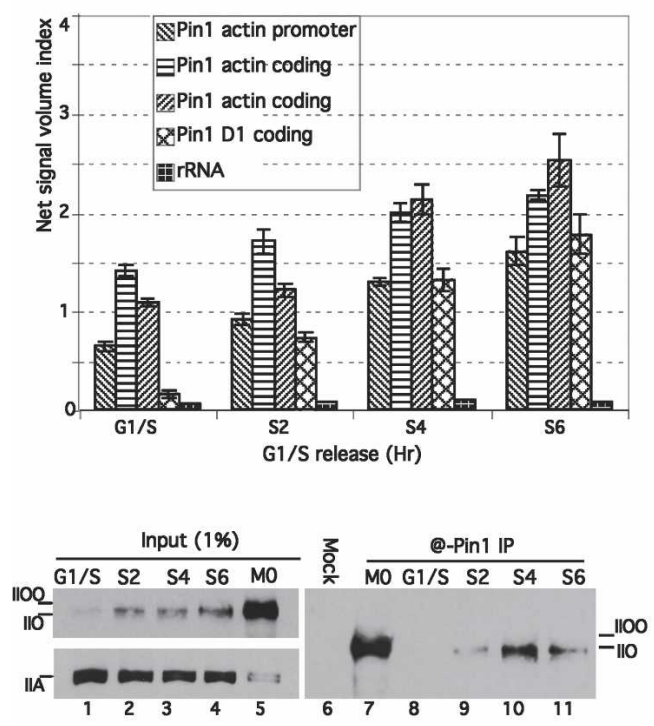

B
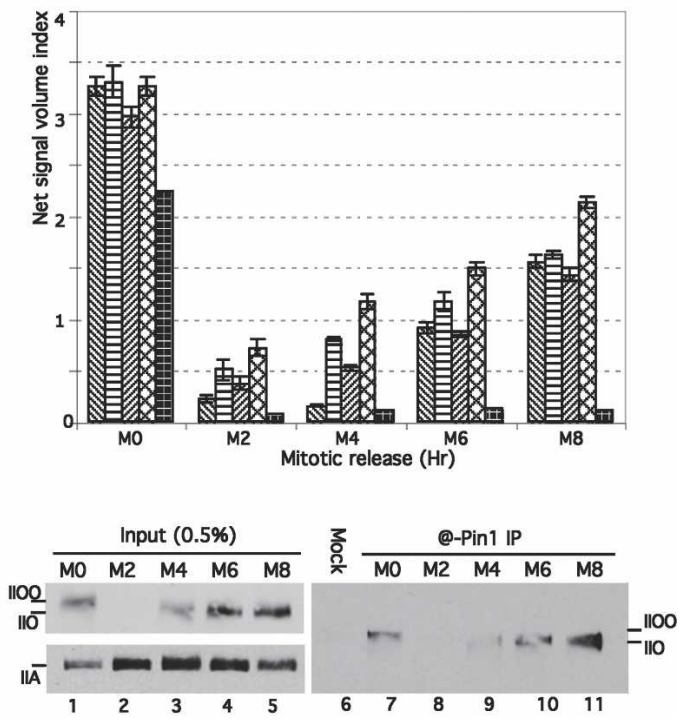

Figure 4. Pin 1 associates with G1/S-phase RNAP IIO and with transcribing genes. (A) HeLa ChIP and NEs were prepared from cells released from a G1/S block at the times indicated. (Top panel) ChIP experiments were performed with anti-Pin1 antibodies, and products were amplified with primers for the $\beta$-actin gene at the promoter, coding, and poly(A) regions; for the cyclin D1 gene at the coding region; and for 28S RNA genes. Aliquots of the NEs were immunoprecipitated with anti-Pin1 antibody (@-Pin1 IP) or rabbit IgG (Mock). (Bottom panel) IPs were analyzed by Western blots probed with H14 antibodies. The input blot was also probed with 8 WG16. (B) Similar ChIP and IP experiments were performed as in $A$, but with extracts prepared from cells released from M-phase arrest.

Pin1 did interact with S-phase RNAP IIO (Fig. 4A, lane 9) and became increasingly associated with the RNAP IIO as $\mathrm{S}$ phase proceeded (Fig. 4A, lanes 10,11). Pin1 co-IPs were also performed with NEs from HeLa cells released from $M$ phase (see Supplementary Fig. 1C for cell cycle profile). HeLa cells were arrested with nocodazole and released as above, and NEs were prepared every $2 \mathrm{~h}$. Figure 4B (bottom) shows that following mitosis, RNAP IIOO was extensively dephosphorylated, and the majority of RNAP II was the IIA isoform (lane 2), as observed in G1/S cells. A similar co-IP pattern as with the S-phase extracts was obtained: No interaction was detected in the extract prepared from cells immediately following mitosis (Fig. 4B, lane 8), but increasing interaction was observed as RNAP II was rephosphorylated in $\mathrm{S}$ phase (Fig. 4B, lanes 9-11). These data indicate that Pin1 associates with transcriptionally active RNAP II in G1/S phase.

To investigate whether Pin1 might play a role in Sphase transcription, we performed ChIP assays with anti-Pin1 antibodies. Extracts were prepared from S-phase cells as above, and the ChIP products were amplified with primers for the promoter, coding, and poly $(\mathrm{A})$ regions of the $\beta$-actin gene and coding region of the cyclin D1 gene. The results (Fig. 4A, top) show that Pin 1 associates increasingly with all regions of the $\beta$ actin gene as $S$ phase proceeds. Similar results were obtained with the cyclin D1 gene, and negligible cross-linking was detected to the 28S rRNA gene (Fig. 4A). We also performed Pin1 ChIP assays with extracts prepared from cells released from $M$ phase. The data in Figure 4B (top) indicate a very strong association of Pin 1 with mitotic chromatin, which we previously showed reflects a function of Pinl in mitotic chromosome condensation $(\mathrm{Xu}$ and Manley 2007), as well as a weaker association with G1/S-phase chromatin following mitosis. The association of Pin1 with G1/S-phase active genes suggests that Pin 1 is involved in the transcription process, and the similar pattern of association of Pin 1 with active genes and with RNAP II in G1/S phase suggests that the function of Pin 1 in transcription is related to CTD phosphorylation during the transcription cycle.

\section{Pin1 inhibits RNAP II transcription in vitro}

The above results prompted us to investigate the function of Pin 1 during the transcription cycle. For this purpose, we first performed in vitro transcription assays with HeLa NE in the presence or absence of purified recombinant wild-type or R68,69A mutant Pin1. Our previous work (Xu et al. 2003) showed that NE prepared from wild-type but not mutant Pin1-overexpressing cells displayed reduced transcriptional activity, but it was unclear whether this was due to a direct effect of Pin1. To address this, and to examine specifically the role of Pin1 in S-phase transcription, NE was prepared from S-phase cells as described above, and CMV promoter-containing linearized DNA was used as template. Figure 5A (top) indicates that addition of wild-type recombinant Pin 1 inhibited transcription in a concentration-dependent manner (lanes 2-4), while mutant Pin1 actually enhanced transcription, indicating a possible dominant-negative effect (lanes 5-7). To rule out nonspecific effects and to show that Pin1-mediated inhibition/ 
A
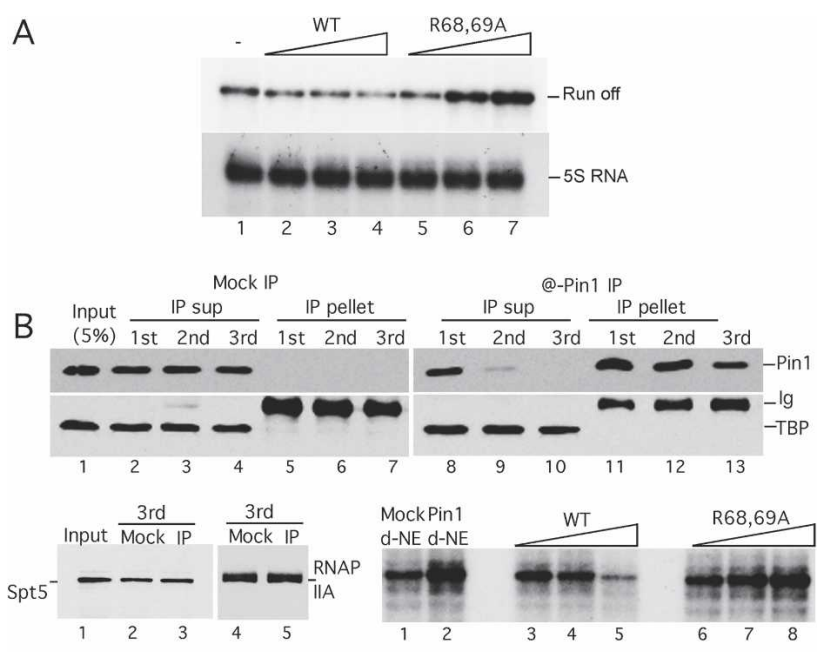

C
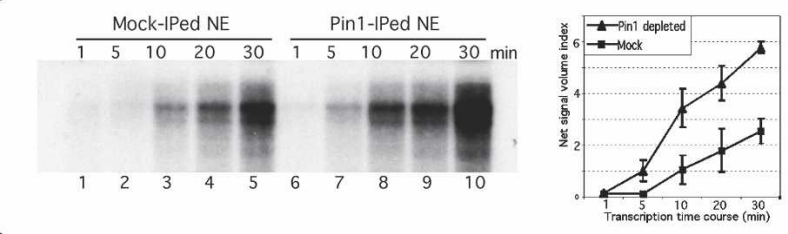

D

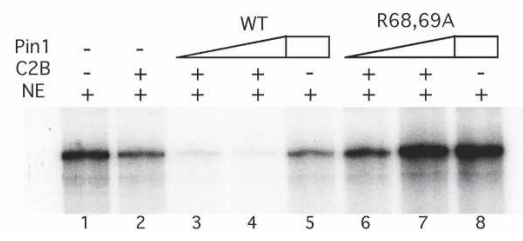

Figure 5. Pin 1 inhibits transcription in vitro. $(A)$ Linearized CMV promoter-containing DNA templates or templates containing the 5S RNA gene were transcribed in NE without (lane 1) or with increasing amounts $(50,100$, and $200 \mathrm{ng})$ of wild-type (lanes 2-4) or R68,69A mutant (lanes 5-7) Pin1. RNA transcripts were analyzed by $7 \mathrm{M}$ urea/6\% PAGE. (B, top panel) NEs were sequentially immunodepleted with rabbit Ig (Mock IP, left) or Pin1 antibody (@Pin1 IP, right). The IP products (IP pellet) or depleted NE (IP sup) were analyzed by Western blotting. Blots were probed with anti-Pin1 (top), anti-TBP (middle), and antiSpt5 and 8WG16 (bottom, left) antibodies. (Bottom panel) Similar transcription assays as in $A$ but with mock-depleted (lane 1), Pin1-depleted NE (lane 2), or Pin1-depleted NE in the presence of increasing amounts of recombinant wild-type (lanes 3-5) or R68,69A mutant (lanes 6-8) Pin1. (C) Mock- or Pin1-depleted NEs were used for in vitro transcription with the CMV-containing DNA templates for the indicated times (left) and transcription products were quantified (right). (D) CMV promoter-containing DNA templates were transcribed in NE (lane 1), or plus various combinations of recombinant cdc2/cyclinB, wild-type, or R68,69A mutant Pin 1 proteins as indicated.

activation targets CTD-containing RNAP II, similar experiments were performed with a DNA template containing the 5S RNA gene. The addition of either wild-type or mutant Pin1 had no effect on 5S RNA transcription (Fig. 5A, bottom).

To extend the above results, we next performed in vitro transcription with NE lacking Pin1. To this end, endogenous Pinl was depleted from NE by sequential immunodepletions with anti-Pin1 antibodies. Pin1-depleted or mock-depleted extracts and the pellets were examined by Western blots probed with anti-Pin1, TBP, Spt5, and RNAP II antibodies. The results (Fig. 5B) show that Pin 1 was efficiently removed from the extract and almost undetectable in the third depleted extract (Fig. $5 \mathrm{~B}$, lane 10). The immunodepletion was specific since TBP, Spt5, and RNAP IIA levels did not change in the mock- or Pin1-depleted NEs (Fig. 5B, bottom panel, lanes 2-4 and 8-10, bottom left panel, lanes $2-3$ and $4-5$, respectively). The NEs were then used in transcription assays again with the CMV promoter-containing template. Figure 5B (bottom right panel) shows that Pin 1 depletion significantly increased transcription compared with that observed in the mock-depleted extract (cf. lanes 1 and 2). Addition of wild-type Pin1 reduced transcription, but mutant Pin1 only slightly stimulated it, suggesting that the dominant-negative effect observed in Figure 5A might be dependent on endogenous Pin 1 (lanes 3-5 and $6-8$, respectively). The increase was further reflected in time-course experiments, in which depletion of Pin1 increased transcription efficiency at all time points (Fig. 5C). These results indicate that Pin1 levels can have a direct effect on RNAP II transcription.

A possible explanation for the above results is that Pin1 might function together with a CTD kinase to hyperphosphorylate and inactivate RNAP II. Indeed, we showed previously that Pin1 stimulates CTD phosphorylation by cdc2/cyclin B in vitro (Xu et al. 2003), suggesting that this kinase together with Pin1 may be responsible for transforming S-phase RNAP IIO to mitotic IIOO. To examine whether Pin1 and cdc2/cyclinB have a synergistic effect on RNAP II transcription in vitro, we performed in vitro transcription in NE supplemented with purified cdc2/cyclin B and Pin1 (Fig. 5D). As expected, cdc2/cyclin B alone inhibited transcription (Fig. 5D, lane 2). Importantly, addition of wild-type, but not mutant, Pin 1 strongly enhanced inhibition (Fig. 5D, lanes 3,4 and 6,7 , respectively). Inhibition was significantly greater than obtained with equivalent amounts of Pinl alone (Fig. 5D, lane 5), indicating a cooperative effect of Pin1 and cdc2/cyclin B in repressing RNAP II transcription.

\section{Pin1 functions in RNAP II transcription initiation, but not elongation, in vitro}

We next set out to investigate the mechanism by which Pin1 represses RNAP II transcription. Specifically, we wished to distinguish between effects on transcription initiation and elongation. To monitor initiation, template DNA was incubated with NE to allow PIC formation, then NTP mix without GTP was added and incubated for $5 \mathrm{~min}$, and the mixture was pulse-labeled with $\left[\alpha{ }^{-32}\right.$ P]GTP for $30 \mathrm{sec}$ (Fig. 6A, lane 1) or incubated for 10 min (Fig. 6A, lane 2). The results indicate that the pulse labeling resulted in short transcripts ( 16 nucleotides) and continuing incubation generated full-length transcripts with disappearance of the short transcripts, indicating that the short RNAs were early initiation prod- 

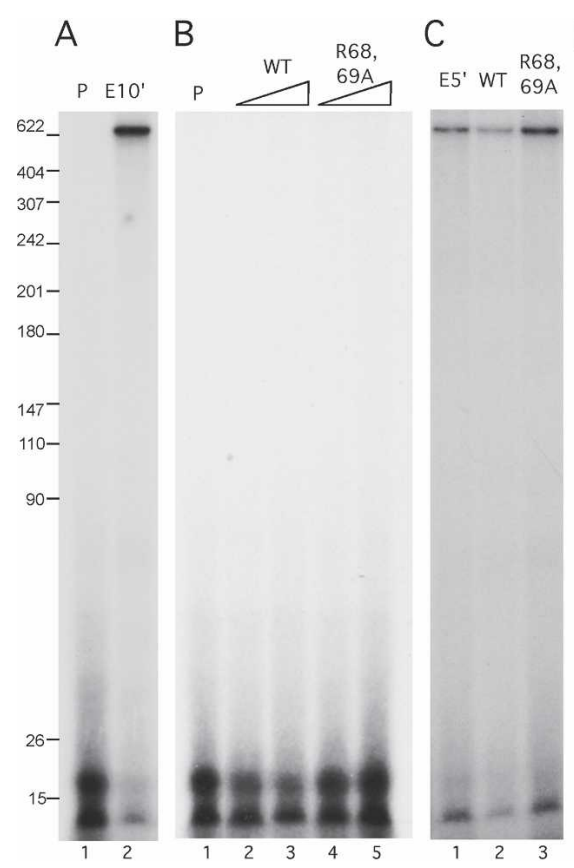

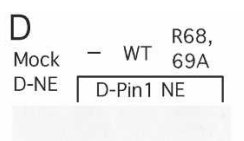

$E$

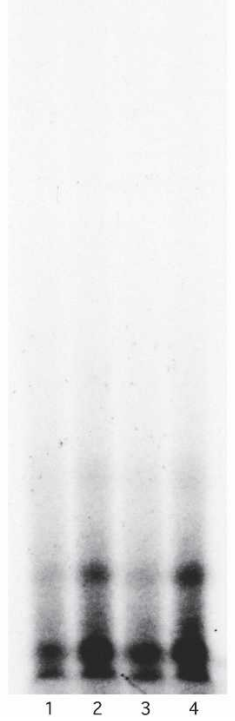

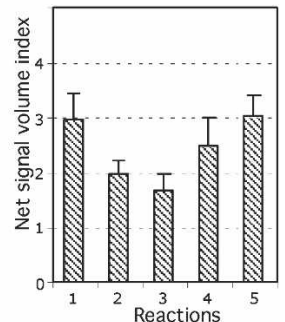

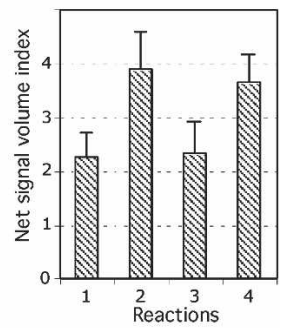

Figure 6. Pin 1 inhibits transcription initiation in vitro. (A) Linear CMV promoter-containing DNA templates were preincubated with $\mathrm{NE}$ for $10 \mathrm{~min}$ at $30^{\circ} \mathrm{C}$, then pulse-labeled with $\left[\alpha{ }^{32} \mathrm{P}\right] \mathrm{UTP}$ for $30 \mathrm{sec}$ at room temperature (lane 1) or supplemented with cold NTPs and incubated for $10 \mathrm{~min}$ at $30^{\circ} \mathrm{C}$ (lane 2). (B) The same DNA templates were preincubated with NE as in $A$ but pulse-labeled without (lane 1) or with 100 and $200 \mathrm{ng}$ of wild-type (lanes 2,3) or R68,69A mutant (lanes 4,5) Pin1. (C) Linearized DNA templates were preincubated and pulse-labeled as in $B$, but with cold NTPs only (lane 1) or plus $200 \mathrm{ng}$ of wild-type (lane 2) or R68,69A mutant (lane 3) Pin1 and then incubated for $5 \mathrm{~min}$ at $30^{\circ} \mathrm{C}$. $(D)$ Similar pulse experiment as $B$ but with mock-depleted (lane 1), or Pin1-depleted (lane 2) NEs as in Figure 5, or Pin1-depleted NE plus wild-type (lane 3) or R68,69A mutant (lane 4) Pin1. (E) Quantitative analyses of data from three independent experiments as in $B$ (top) and $D$ (bottom). ucts. Synthesis of the short RNAs was inhibited by $\alpha$ amanitin, while addition of DRB inhibited production of full-length transcripts but not the short products /data not shown). Addition of wild-type Pin1 significantly inhibited accumulation of the early transcripts in a concentration-dependent manner (Fig. 6B [lanes 2,3, 48\% and $\sim 76 \%$ reduction], E [top]), but mutant Pin 1 slightly stimulated their formation (Fig. 6B, lanes 4,5). To ensure that the short products reflect elongation intermediates, pulse-labeling reactions analogous to those in Figure 6B were incubated for $5 \mathrm{~min}$ at $30^{\circ} \mathrm{C}$. The results (Fig. 6C) revealed a similar pattern as in Figure 5, with mutant Pin1 stimulating elongation (Fig. 6C, lane 3), but wildtype Pin 1 reducing accumulation of run-off products (Fig. 6C, lane 2). To extend these findings, we also used Pin1- or mock-depleted NE for the initiation assay. Depletion of Pin1 significantly increased formation $(\sim 42 \%)$ of initiation products (Fig. 6D [lanes 1,2], E [bottom]), and the increase was inhibited by addition of wildtype (Fig. 6D, lane 3), but not mutant (Fig. 6D, lane 4), Pin1. The data strongly suggest that Pin 1 functions early in the process of transcription initiation.

The above results indicate that Pin 1 represses RNAP II transcription at an early stage, either at initiation or very early during elongation. To examine the effect of Pin 1 on elongation per se, we first used an immobilized template assay. Biotin-labeled DNA templates, again containing the CMV promoter, were conjugated with streptavidin beads, preincubated with NE for PIC formation, and then pulse-labeled with $\left[\alpha-{ }^{32} \mathrm{P}\right] \mathrm{GTP}$. After extensive washing, reaction mixtures were supplied with cold NTPs in the absence or presence of wild-type or mutant Pin1. Strikingly, neither protein had a significant effect on transcription elongation (Fig. 7A). To confirm this result, we used a DNA template containing the CMV promoter and a G-less cassette following the +1 position /Cho et al.
1999|. The templates were preincubated with NE and then supplied with ATP, CTP, and $\left[\alpha-{ }^{32} \mathrm{P}\right] \mathrm{UTP}$ for 10 min. As expected, elongation complexes stalled at the end of the G-less cassette. Addition of excess amounts of all four NTPs allowed elongation to continue. Again, neither wild-type nor mutant Pin1 had any significant effect on elongation (Fig. 7B). Taken together, our in vitro data indicate that, under the conditions used, Pin1 plays a crucial role in an early stage of RNAP II transcription, but not in elongation.

\section{Discussion}

We previously presented evidence that Pin 1 modulates the phosphorylation status of RNAP II and helps to regulate its activities in both transcription and pre-mRNA processing (Xu et al. 2003). Extending these findings, in this study we have demonstrated that Pin 1 activity can control the association of RNAP II with active genes throughout the cell cycle, by modulating CTD phosphorylation. Pin1 can also influence the nuclear distribution of RNAP II, as Pin1-overexpression caused RNAP II to accumulate in enlarged speckle-associated structures. Pin 1 directly participates in transcription and functions specifically at the initiation, and not the elongation, stage in in vitro assays. Thus our data suggest multiple functions for Pin1 in regulating RNAP II activities in both the cell cycle and the transcription cycle.

\section{Pin1 and cell cycle regulation of RNAP II}

Our study has demonstrated a direct relationship between Pin1 and control of RNAP II activity during the cell cycle. It has long been known that mRNA synthesis is repressed during mitosis (Gottesfeld and Forbes 1997), 


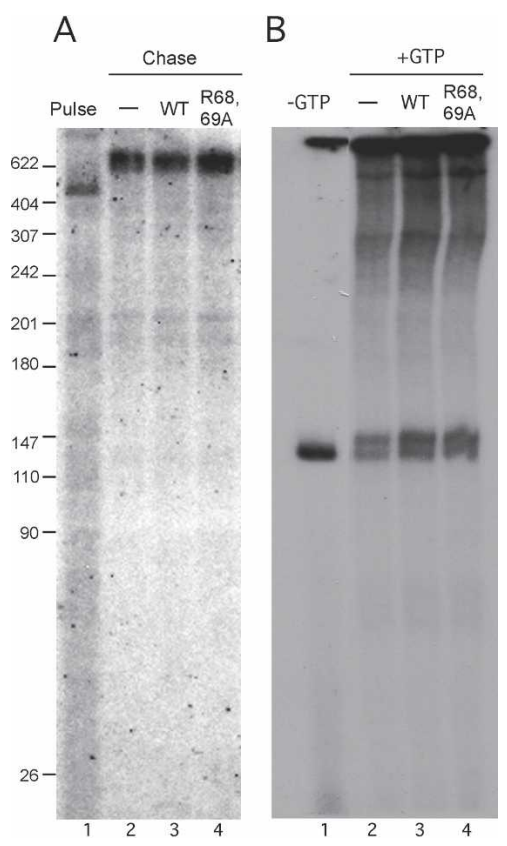

Figure 7. Pin 1 does not affect transcription elongation in vitro. (A) Biotin-labeled immobilized DNA templates were preincubated with $\mathrm{NE}$ for $10 \mathrm{~min}$ at $30^{\circ} \mathrm{C}$ and then pulse-labeled with $\left[\alpha-{ }^{32} \mathrm{P}\right]$ GTP for $30 \mathrm{sec}$ at room temperature (lane 1), or pelleted with magnet beads and extensively washed, then chased with cold NTPs only (lane 2) or plus 200 ng of wild-type (lane 3) or R68,69A mutant (lane 4) recombinant Pinl for 5 min. (B) Linearized CMV promoter-containing DNA templates, which contain a G-less cassette following the +1 position, were preincubated with NE for $10 \mathrm{~min}$ at $30^{\circ} \mathrm{C}$, and incubated with ATP, CTP, and UTP plus $\left[\alpha-{ }^{32} \mathrm{P}\right] \mathrm{UTP}$ for $10 \mathrm{~min}$ (lane 1), or supplemented with cold GTP only (lane 2) or plus 200 ng of wild-type (lane 3) or R68,69A mutant (lane 4) Pin1 for $10 \mathrm{~min}$ at $30^{\circ} \mathrm{C}$.

which reflects in part reduced mitotic RNAP II activity. It was previously shown that RNAP II is physically excluded from mitotic chromosomes (Parsons and Spencer 1997; Christova and Oelgeschlager 2002). Consistent with and extending these findings, our data have shown that RNAP II dissociates from active genes in a manner regulated by Pin1-modulated CTD phosphorylation. Notably, chromosomal DNA undergoes a dramatic topological change in G2/M phase, from highly extended in $\mathrm{S}$ phase to the tightly condensed mitotic form. The condensation process itself is not required for the displacement of RNAP II from mitotic chromosomes. For example, viral DNA in HSV-infected HeLa cells does not condense in $\mathrm{M}$ phase, but the viral genome fails to engage with RNAP II during mitosis (Spencer et al. 2000). Nonetheless, exclusion of RNAP II from mitotic chromosomes is likely an integral part of the condensation process, and it is intriguing that Pin1 in fact participates directly in chromosome condensation. Pinl stimulates the massive phosphorylation of mitotic phosphoproteins, including Topoisomerase (Topo) II $\alpha$, and also promotes the association of phosphorylated TopoII $\alpha$ with DNA to form a scaffold axis for mitotic chromosome assembly (Xu and Manley 2007). This process occurs dur- ing G2/M phase, and the Pin1-mediated disassociation of RNAP II could thus occur simultaneously with the stepwise process of chromosome condensation.

Increased phosphorylation of transcription factors in mitosis is not restricted to RNAP II. For example, TBP and several TAFII subunits of TFIID are hyperphosphorylated at mitosis and this is required for repression of activator-dependent transcription (Leresche et al. 1996; Segil et al. 1996; Long et al. 1998). It has also been observed that many transcription factors are also displaced from the promoter regions of mitotic chromosomes (Martinez-Balbas et al. 1995; Parsons and Spencer 1997). These could all be coordinated events necessary for full mitotic repression. However, not all transcription factors disassociate from mitotic chromosomes. One exceptional case is the TFIID-promoter complex, which was shown to become embedded in condensed chromosomes (Segil et al. 1996; Chen et al. 2002; Christova and Oelgeschlager 2002). While chromosome-bound TFIID is not functional in activator-dependent transcription due to the hyperphosphorylation of several subunits, its presence at promoters may have alternative functions. Packaging of TFIID into promoter regions in mitotic chromosomes may help to pass parental gene expression patterns onto daughter cells (Segil et al. 1996). Following decondensation of chromosomal DNA, the loaded TFIID at the promoter may facilitate recruitment of RNAP II to bring about rapid initiation of transcription in G1 phase. The dephosphorylation of inactive RNAP IIOO, which also occurs in G1 phase (Xu et al. 2003), likely also contributes to transcriptional reactivation.

\section{Phosphorylation-regulated nuclear distribution of RNAP II}

The distribution of RNAP II in the nucleus is dynamic, and is regulated at least in part by changes in CTD phosphorylation. Immunofluorescence studies indicated that a fraction of the total RNAP II is localized in discrete speckle-like domains (Bregman et al. 1995; Zeng et al. 1997). Speckles are also sites enriched in other transcription and mRNA processing factors (Lamond and Spector 2003). More diffuse staining RNAP II forms a reticular network that interconnects the speckle domains (Bregman et al. 1995; Zeng et al. 1997). This distribution pattern is related to the cell's transcription state. Upon addition of transcriptional inhibitors, RNAP IIO redistributes to form enlarged speckle domains, while removal of the inhibitors causes RNAP II to revert to the interconnected speckle pattern (Bregman et al. 1995). These data suggested that speckles might be storage sites for RNAP II. However, this view is not entirely supported by recent studies based on ultrathin cryosection confocal microscopy (Xie et al. 2006), which gives higher resolution of subnuclear structures. This study provided evidence that speckles are not enriched for RNAP II, even in the presence of transcription inhibitors. However, consistent with the previous studies, the speckle domains do contain a stable pool of hyperphosphorylated, transcriptionally inactive RNAP II. This is consistent with our data 
showing that Pin1-induced hyperphosphorylated RNAP II is concentrated largely in multiple dot-like structures that are distinct from speckles, although speckle domains are frequently localized nearby. Interestingly, upon Pin1 overexpression, the speckles were significantly enlarged, similar to the pattern observed following transcription inhibition (Bregman et al. 1995). Given that inducible Pinl overexpression inhibits RNAP II transcription, formation of enlarged speckle domains is strongly associated with inactivation of RNAP II and subsequent RNA processing.

\section{Pin1 regulates RNAP II activities during the transcription cycle}

Our data have shown that Pin1 not only associates with transcriptionally inactive RNAP II, such as the highly phosphorylated IIOO, but also actively participates in the RNAP II transcription cycle. Our ChIP data indicated that Pin 1 is present along the length of transcribed genes during G1/S phase and associates with RNAP IIO. This suggests that Pin 1 has the potential to affect events that occur throughout the transcription cycle, likely reflecting its ability to bind to and influence phosphorylation of the CTD. The inhibitory effect of Pin1 on an early step in initiation highlights the potential importance of controlling CTD phosphorylation and/or conformation. But what might be the basis for this inhibitory effect? It is notable that our depletion experiments showed that even endogenous levels of Pin1 are inhibitory, suggesting that Pin 1 plays a naturally repressive role. One possibility is that Pin1 binding to the phosphorylated CTD simply competes or interferes with other important interactions. This seems unlikely given that the phosphorylated CTD adapts an extended conformation, even when bound to Pin1 (Verdecia et al. 2000), which presents multiple potential interaction sites. Another possibility is that excess CTD phosphorylation and/or conformational changes mediated by Pin 1 are inhibitory. This could be analogous to the inactivity of the mitotic RNAP IIOO isoform, and might suggest that a fraction of interphase RNAP II is maintained in an inactive state via Pinl activity. Finally, it could be that another general transcription factor is repressed by Pin1, although evidence for the existence of such a target is lacking.

It was unexpected that Pin1 levels had no effect on transcription elongation in our in vitro assays, especially in light of our finding that it is present along the length of transcribed genes in vivo. One possibility is that Pin1 does indeed influence elongation, but only on chromatin templates. Consistent with this notion, genetic analyses in yeast indicate that Ess1 may play roles both in initiation and elongation (Wu et al. 2000; Wilcox et al. 2004). Furthermore, Pin 1 has been shown to associate with Spt5 (Lavoie et al. 2001), which together with Spt4 functions to facilitate elongation on nucleosome-containing templates (e.g., Wada et al. 1998). Another possibility is that the principal post-initiation effects of Pin 1 involve RNA processing. As discussed above, there is ample evidence that the CTD participates in all the major pre-
mRNA processing reactions, and that CTD phosphorylation is important for these functions. In yeast, Ess1 has been suggested to play a role in 3' end formation (Hani et al. 1999; Morris et al. 1999), and Pin1 can influence CTD-dependent splicing in vitro (Xu et al. 2003). Furthermore, Spt 5 has been suggested to function in RNA processing as well as elongation (e.g., Lindstrom et al. 2003), and its interaction with Pin1 could influence these functions. Pin 1 has also been shown to interact with p54nrb, a multifunctional protein implicated in several steps in transcription and mRNA processing (Proteau et al. 2005). Thus, we suggest that the functional significance of Pinl's association with elongating RNAP II is to facilitate phosphorylation-dependent interactions between a variety of factors, including but not limited to the CTD, that are involved in processing newly synthesized transcripts.

\section{Materials and methods}

Cell culture, stable Pin1-expressing cell lines, and cell extracts

HeLa cells were cultured in DMEM supplemented with $10 \%$ FBS. Stable cell lines expressing flu-tagged wild-type and R68,69A mutant Pin1 were described previously (Xu et al. 2003). Cell lines were cultured in DMEM media containing $10 \%$ tet-free FBS (Clontech). Expression of wild-type and mutant Pin 1 and total cell extracts were essentially as described previously (Xu et al. 2003).

\section{HeLa cell cycle analysis and ChIP assays}

To obtain pure mitotic cells, HeLa cells were treated with nocodazole (100 ng/mL; Sigma) for $12 \mathrm{~h}$, then released in normal media and harvested at the indicated time points. The cell cycle analysis was performed essentially as reported previously (Xu and Manley 2007). Briefly, HeLa cells were synchronized at the boundary of G1/S phases with two rounds of thymidine treatment, released into the cell cycle, and harvested every $2 \mathrm{~h}$. To obtain pure M-phase cell populations, nocodazole was added to the released cells at the 8 -h time point, and the cells were incubated for an additional 4 or $6 \mathrm{~h}$. G1 cells were obtained by releasing cells from the 6 -h nocodazole treatment. At the indicated time points, cells were harvested and extracts were prepared for ChIP and Western analysis. Cell cycle profiles were confirmed by flow cytometry (Xu and Manley 2007). ChIP extracts were prepared as described previously ( $\mathrm{Xu}$ and Manley 2007). The extracts were precleared for $4 \mathrm{~h}$ at $4^{\circ} \mathrm{C}$ with antimouse IgM antibodies coupled to agarose beads (Sigma) for H5 and H15 ChIP and Staphylococcus aureus protein-A-positive cells for Pinl ChIP, which were blocked with TE buffer containing $1 \mu \mathrm{g} / \mathrm{mL}$ sheared salmon sperm DNA and $1 \mu \mathrm{g} / \mathrm{mL}$ BSA for $4 \mathrm{~h}$ at $4^{\circ} \mathrm{C}$. The precleared chromatin concentration was measured by O.D. at $260 \mathrm{~nm}$, and equal amounts of chromatin DNA from different time points were rotated with $\sim 1 \mu \mathrm{g}$ of anti-RNAP II H5 and H14 monoclonal (Covance) or polyclonal anti-Pin1 antibodies (Calbiochem), or mock antibodies, such as anti-mouse IgM or rabbit IgG, in a buffer containing $20 \mathrm{mM}$ Tris (pH 8.0), 140 mM NaCl, 1 mM EDTA, 1\% Triton X-100, 0.1\% sodium deoxycholate, $0.1 \%$ SDS, and $2 \mathrm{mM}$ PMSF for $\sim 12 \mathrm{~h}$ at $4^{\circ} \mathrm{C}$. Chromatin was centrifuged, and the blocked anti-mouse IgM agarose or $S$. aureus protein-A beads were added to the supernatant and rotated for $2 \mathrm{~h}$ at $4^{\circ} \mathrm{C}$. The beads were then 
pelleted and washed at room temperature twice with binding buffer, twice with the same buffer but containing $275 \mathrm{mM}$ $\mathrm{NaCl}$, four times with the same buffer but with $500 \mathrm{mM} \mathrm{NaCl}$, and twice with TE. Precipitated chromatin was eluted with a buffer containing $50 \mathrm{mM} \mathrm{NaHCO} 3$ and $1 \%$ SDS, digested with protease $\mathrm{K}$ and RNase $\mathrm{A}$ for $2 \mathrm{~h}$ at $55^{\circ} \mathrm{C}$ in $\mathrm{TE}$ buffer with $1 \%$ SDS, and cross-links were reversed overnight at $65^{\circ} \mathrm{C}$. DNA was extracted, precipitated, and dissolved in TE $(30 \mu \mathrm{L})$. Various primer sets were synthesized from promoter, coding, and poly(A) regions of $\beta$-actin or cyclin D1 and from 28S rRNA genes. Primers were screened in the preliminary PCR tests, and only the primer sets that generate similar signals were included in the ChIP experiments. Amplification was carried out in a standard PCR reactions containing $2 \mu \mathrm{L}$ of DNA with Taq DNA polymerase (Invitrogen) and $0.1 \mu \mathrm{Ci}$ of $\left[{ }^{32} \mathrm{P}\right] \mathrm{dCTP}$ for 25 cycles. Products were resolved by $6 \%$ denaturing PAGE. Quantitative data for each ChIP experiment were obtained from PhosphorImager and analyzed with ImageQuant 5.2 (Molecular Dynamics), and net signals were calculated by subtracting the values of each PCR product from the signal of mock antibodies. Standard errors were calculated from at least three independent experiments in this study.

\section{Confocal immunofluorescence}

Wild-type and R68,69A mutant cell lines were seeded on coverslips and incubated without or in presence of doxycycline (1 $\mu \mathrm{g} / \mathrm{mL}$ ) for $12 \mathrm{~h}$. The cells were washed in PBS and fixed with $3 \%$ paraformaldehyde for $10 \mathrm{~min}$. After washing, fixed cells were permeablized with Triton X-100 buffer $(0.5 \%$ Triton $\mathrm{X}-100,20 \mathrm{mM}$ HEPES-KOH at $\mathrm{pH} 7.9,50 \mathrm{mM} \mathrm{NaCl}, 3 \mathrm{mM}$ $\mathrm{MgCl}_{2}, 300 \mathrm{mM}$ sucrose). Cells were then blocked and incubated with anti-RNAP II H5, H14, 8WG16, or N20; anti-Pin1 or anti-SC35 antibodies; and appropriate secondary antibodies. Coverslips were mounted in mounting media (Vector Laboratories), and cells were visualized by confocal microscopy.

Preparation of NEs, immunoprecipitation, and immunodepletion

Mitotic extracts were prepared as described before (Xu and Manley 2007). NEs from the cells released from mitotic or G1/S HeLa cells were prepared as described (Xu et al. 2003). For immunoprecipitation, protein-A agarose was conjugated with Pin 1 polyclonal antibody $(2 \mu \mathrm{g})$ or a similar amount of rabbit IgG overnight at $4^{\circ} \mathrm{C}$. Beads were then washed twice and mixed with extracts in Buffer D. The resulting mixtures were rotated for $1 \mathrm{~h}$ at $4^{\circ} \mathrm{C}$ and centrifuged. Beads were extensively washed and resuspended in SDS sample buffer. Sequential Pin1 immunodepletions were carried out as described (Xu and Manley 2007), but with S-phase NEs.

\section{Protein purification and in vitro transcription}

Recombinant GST-tagged wild-type, mutant R68,69A Pin1 proteins, and cdc2/cyclin B were purified as described (Xu et al. 2003). The GST tag was removed by PreScission protease (Amersham) according to the protocol provided. Standard in vitro transcription was performed with DNA templates (500 ng) in a buffer containing $3 \mu \mathrm{L}$ of S-phase or Pin1- or mock-depleted NEs, 9 mM HEPES (pH 7.9), $3 \mathrm{mM} \mathrm{MgCl}_{2}, 44 \mathrm{mM} \mathrm{KCl}, 8.8 \%$ glycerol, $0.88 \mathrm{mM}$ EDTA, $0.22 \mathrm{mM}$ DTT, and $400 \mu \mathrm{M} \mathrm{ATP}$, CTP, UTP plus $160 \mu \mathrm{M}$ GTP, and $1 \mu \mathrm{Ci}$ of $\left[\alpha-{ }^{32} \mathrm{P}\right] \mathrm{GTP}$ for 30 min at $30^{\circ} \mathrm{C}$. Pulse labeling was performed in a buffer containing $10 \mathrm{mM}$ HEPES ( $\mathrm{pH} 7.9$ ), $3 \mathrm{mM} \mathrm{MgCl}, 50 \mathrm{mM} \mathrm{KCl}, 10 \%$ glycerol, $1 \mathrm{mM}$ EDTA, and $0.25 \mathrm{mM}$ DTT. Specifically, DNA templates were preincubated with $3 \mu \mathrm{L}$ of S-phase or Pin1- or mock-depleted NEs for PIC formation for $10 \mathrm{~min}$ at $30^{\circ} \mathrm{C}$. When appropriate, recombinant proteins were added after the preinitiation. Reaction mixtures were supplied with $0.5 \mathrm{mM}$ ATP, CTP, and UTP in the same buffer for $5 \mathrm{~min}$ at room temperature and pulse-labeled with $1 \mu \mathrm{Ci}$ of $\left[\alpha{ }^{3}{ }^{32} \mathrm{P}\right] \mathrm{GTP}$ for $\sim 30 \mathrm{sec}$ at room temperature. Reactions were either terminated or supplied with cold GTP for $10 \mathrm{~min}$ at $30^{\circ} \mathrm{C}$. The pulse-chase analysis with immobilized DNA templates was performed as described (Adamson et al. 2003). Linear DNA templates were generated by PCR with one biotin-labeled primer, and biotin-labeled DNA was conjugated with the streptavidin-coated beads (Dynabeads M-280; Dyna Biotech) according to the protocol provided. In vitro transcription with G-less DNA templates was carried out essentially as reported previously (Cho et al. 1999). The DNA template was constructed by inserting a G-less cassette (135 base pairs) into the +1 position following a CMV promoter and confirmed by DNA sequencing. Linearized DNA templates were incubated with NE for PIC, and supplied with $0.5 \mathrm{mM}$ ATP, CTP and $160 \mu \mathrm{M}$ UTP and $1 \mu \mathrm{Ci}$ of $\left[\alpha-{ }^{32} \mathrm{P}\right] \mathrm{UTP}$ for $10 \mathrm{~min}$ at $30^{\circ} \mathrm{C}$; reactions were either terminated or supplied with normal amounts of cold GTP plus or minus wild-type or mutant Pin 1 proteins for $10 \mathrm{~min}$ at $30^{\circ} \mathrm{C}$.

\section{Acknowledgments}

We are grateful to $\mathrm{H}$. Handa for the anti-Spt5 polyclonal antibody, and I. Boluk for help with the manuscript. This work was supported by NIH grant GM37971 to J.L.M.

\section{References}

Adamson, T.E., Shore, S.M., and Price, D.H. 2003. Analysis of RNA polymerase II elongation in vitro. Methods Enzymol. 371: 264-275.

Ahn, S.H., Kim, M., and Buratowski, S. 2004. Phosphorylation of serine 2 within the RNA polymerase II C-terminal domain couples transcription and $3^{\prime}$ end processing. Mol. Cell 13: 67-76.

Albert, A., Lavoie, S., and Vincent, M. 1999. A hyperphosphorylated form of RNA polymerase II is the major interphase antigen of the phosphoprotein antibody MPM-2 and interacts with the peptidyl-prolyl isomerase Pin1. J. Cell Sci. 112: 2493-2500.

Bregman, D.B., Du, L., van der Zee, S., and Warren, S.L. 1995. Transcription-dependent redistribution of the large subunit of RNA polymerase II to discrete nuclear domains. I. Cell Biol. 129: 287-298.

Chen, D., Hinkley, C.S., Henry, R.W., and Huang, S. 2002. TBP dynamics in living human cells: Constitutive association of TBP with mitotic chromosomes. Mol. Biol. Cell 13: 276-284.

Cho, H., Kim, T.K., Mancebo, H., Lane, W.S., Flores, O., and Reinberg, D. 1999. A protein phosphatase functions to recycle RNA polymerase II. Genes \& Dev. 13: 1540-1552.

Cho, E.J., Kobor, M.S., Kim, M., Greenblatt, J., and Buratowski, S. 2001. Opposing effects of Ctk1 kinase and Fcp1 phosphatase at Ser 2 of the RNA polymerase II C-terminal domain. Genes \& Dev. 15: 3319-3329.

Christova, R. and Oelgeschlager, T. 2002. Association of human TFIID-promoter complexes with silenced mitotic chromatin in vivo. Nat. Cell Biol. 4: 79-82.

Cramer, P., Bushnell, D.A., and Kornberg, R.D. 2001. Structural basis of transcription: RNA polymerase II at $2.8 \AA$ resolution. Science 292: 1863-1876. 
Dahmus, M.E. 1996. Reversible phosphorylation of the C-terminal domain of RNA polymerase II. J. Biol. Chem. 271: 19009-19012.

Fabrega, C., Shen, V., Shuman, S., and Lima, C.D. 2003. Structure of an mRNA capping enzyme bound to the phosphorylated carboxy-terminal domain of RNA polymerase II. Mol. Cell 11: 1549-1561.

Fisher, G. 1994. Peptidyl-prolyl cis/trans isomerase and their effectors. Angew. Chem. Int. Ed. Engl. 33: 1415-1436.

Gottesfeld, J.M. and Forbes, D.J. 1997. Mitotic repression of the transcriptional machinery. Trends Biochem. Sci. 22: 197202.

Hani, J., Schelbert, B., Bernhardt, A., Domdey, H., Fischer, G., Wiebauer, K., and Rahfeld, J.U. 1999. Mutations in a peptidylprolyl-cis/trans-isomerase gene lead to a defect in 3 '-end formation of a pre-mRNA in Saccharomyces cerevisiae. J. Biol. Chem. 274: 108-116.

Hirose, Y. and Manley, J.L. 2000. RNA polymerase II and the integration of nuclear events. Genes \& Dev. 14: 1415-1429.

Komarnitsky, P., Cho, E.J., and Buratowski, S. 2000. Different phosphorylated forms of RNA polymerase II and associated mRNA processing factors during transcription. Genes \& Dev. 14: 2452-2460.

Lamond, A.I. and Spector, D.L. 2003. Nuclear speckles: A model for nuclear organelles. Nat. Rev. Mol. Cell Biol. 4: 605-612.

Lavoie, S.B., Albert, A.L., Handa, H., Vincent, M., and Bensaude, O. 2001. The peptidyl-prolyl isomerase Pin1 interacts with hSpt5 phosphorylated by Cdk9. J. Mol. Biol. 312: 675-685.

Laybourn, P.J. and Dahmus, M.E. 1989. Transcription-dependent structural changes in the C-terminal domain of mammalian RNA polymerase subunit IIa/o. J. Biol. Chem. 264: 6693-6698.

Leresche, A., Wolf, V.J., and Gottesfeld, J.M. 1996. Repression of RNA polymerase II and III transcription during $M$ phase of the cell cycle. Exp. Cell Res. 229: 282-288.

Lindstrom, D.L., Squazzo, S.L., Muster, N., Burckin, T.A., Wachter, K.C., Emigh, C.A., McCleery, J.A., Yates III, J.R., and Hartzog, G.A. 2003. Dual roles for Spt5 in pre-mRNA processing and transcription elongation revealed by identification of Spt5-associated proteins. Mol. Cell. Biol. 23: 13681378.

Long, J.J., Leresche, A., Kriwacki, R.W., and Gottesfeld, J.M. 1998. Repression of TFIIH transcriptional activity and TFIIH-associated cdk7 kinase activity at mitosis. Mol. Cell. Biol. 18: 1467-1476.

Lu, H., Flores, O., Weinmann, R., and Reinberg, D. 1991. The nonphosphorylated form of RNA polymerase II preferentially associates with the preinitiation complex. Proc. Natl. Acad. Sci. 88: 10004-10008.

Lu, P.J., Zhou, X.Z., Liou, Y.C., Noel, J.P., and Lu, K.P. 2002. Critical role of WW domain phosphorylation in regulating phosphoserine binding activity and Pin1 function. J. Biol. Chem. 277: 2381-2384.

Maniatis, T. and Reed, R. 2002. An extensive network of coupling among gene expression machines. Nature 416: 499506.

Martinez-Balbas, M.A., Dey, A., Rabindran, S.K., Ozato, K., and Wu, C. 1995. Displacement of sequence-specific transcription factors from mitotic chromatin. Cell 83: 29-38.

McCracken, S., Fong, N., Rosonina, E., Yankulov, K., Brothers, G., Siderovski, D., Hessel, A., Foster, S., Shuman, S., and Bentley, D.L. 1997. 5'-Capping enzymes are targeted to premRNA by binding to the phosphorylated carboxy-terminal domain of RNA polymerase II. Genes \& Dev. 11: 3306-3318.

Meinhart, A. and Cramer, P. 2004. Recognition of RNA polymerase II carboxy-terminal domain by 3 '-RNA-processing factors. Nature 430: 223-226.

Meinhart, A., Kamenski, T., Hoeppner, S., Baumli, S., and Cramer, P. 2005. A structural perspective of CTD function. Genes \& Dev. 19: 1401-1415.

Meredith, G.D., Chang, W.H., Li, Y., Bushnell, D.A., Darst, S.A., and Kornberg, R.D. 1996. The C-terminal domain revealed in the structure of RNA polymerase II. J. Mol. Biol. 258: 413419.

Morris, D.P., Phatnani, H.P., and Greenleaf, A.L. 1999. Phospho-carboxyl-terminal domain binding and the role of a prolyl isomerase in pre-mRNA 3 '-end formation. J. Biol. Chem. 274: 31583-31587.

Myers, L.C. and Kornberg, R.D. 2000. Mediator of transcriptional regulation. Annu. Rev. Biochem. 69: 729-749.

Ni, Z., Schwartz, B.E., Werner, J., Suarez, J.R., and Lis, J.T. 2004. Coordination of transcription, RNA processing, and surveillance by P-TEFb kinase on heat shock genes. Mol. Cell 13: 55-65.

Palancade, B., Marshall, N.F., Tremeau-Bravard, A., Bensaude, O., Dahmus, M.E., and Dubois, M.F. 2004. Dephosphorylation of RNA polymerase II by CTD-phosphatase FCP1 is inhibited by phospho-CTD associating proteins. J. Mol. Biol. 335: 415-424.

Parsons, G.G. and Spencer, C.A. 1997. Mitotic repression of RNA polymerase II transcription is accompanied by release of transcription elongation complexes. Mol. Cell. Biol. 17: 5791-5802.

Price, D.H. 2000. P-TEFb, a cyclin-dependent kinase controlling elongation by RNA polymerase II. Mol. Cell. Biol. 20: 26292634.

Proteau, A., Blier, S., Albert, A.L., Lavoie, S.B., Traish, A.M., and Vincent, M. 2005. The multifunctional nuclear protein p54nrb is multiphosphorylated in mitosis and interacts with the mitotic regulator Pin1. J. Mol. Biol. 346: 1163-1172.

Schroeder, S.C., Schwer, B., Shuman, S., and Bentley, D. 2000. Dynamic association of capping enzymes with transcribing RNA polymerase II. Genes \& Dev. 14: 2435-2440.

Segil, N., Guermah, M., Hoffmann, A., Roeder, R.G., and Heintz, N. 1996. Mitotic regulation of TFIID: Inhibition of activator-dependent transcription and changes in subcellular localization. Genes \& Dev. 10: 2389-2400.

Shen, M., Stukenberg, P.T., Kirschner, M.W., and Lu, K.P. 1998. The essential mitotic peptidyl-prolyl isomerase Pin1 binds and regulates mitosis-specific phosphoproteins. Genes \& Dev. 12: 706-720.

Sims III, R.J., Belotserkovskaya, R., and Reinberg, D. 2004. Elongation by RNA polymerase II: The short and long of it. Genes \& Dev. 18: 2437-2468.

Spencer, C.A., Kruhlak, M.J., Jenkins, H.L., Sun, X., and BazettJones, D.P. 2000. Mitotic transcription repression in vivo in the absence of nucleosomal chromatin condensation. J. Cell Biol. 150: 13-26.

Verdecia, M.A., Bowman, M.E., Lu, K.P., Hunter, T., and Noel, J.P. 2000. Structural basis for phosphoserine-proline recognition by group IV WW domains. Nat. Struct. Biol. 7: 639643.

Wada, T., Takagi, T., Yamaguchi, Y., Ferdous, A., Imai, T., Hirose, S., Sugimoto, S., Yano, K., Hartzog, G.A., Winston, F., et al. 1998. DSIF, a novel transcription elongation factor that regulates RNA polymerase II processivity, is composed of human Spt4 and Spt5 homologs. Genes \& Dev. 12: 343356.

Wilcox, C.B., Rossettini, A., and Hanes, S.D. 2004. Genetic interactions with $\mathrm{C}$-terminal domain (CTD) kinases and the CTD of RNA Pol II suggest a role for ESS1 in transcription initiation and elongation in Saccharomyces cerevisiae. Ge- 
netics 167: 93-105.

Wu, X., Wilcox, C.B., Devasahayam, G., Hackett, R.L., ArevaloRodriguez, M., Cardenas, M.E., Heitman, J., and Hanes, S.D. 2000. The Ess1 prolyl isomerase is linked to chromatin remodeling complexes and the general transcription machinery. EMBO J. 19: 3727-3738.

Xie, S.Q., Martin, S., Guillot, P.V., Bentley, D.L., and Pombo, A. 2006. Splicing speckles are not reservoirs of RNA polymerase II, but contain an inactive form, phosphorylated on serine 2 residues of the C-terminal domain. Mol. Biol. Cell 17: $1723-1733$.

Xu, Y.X. and Manley, J.L. 2007. The prolyl isomerase pin1 functions in mitotic chromosome condensation. Mol. Cell 26: 287-300.

Xu, Y.X., Hirose, Y., Zhou, X.Z., Lu, K.P., and Manley, J.L. 2003. Pin 1 modulates the structure and function of human RNA polymerase II. Genes \& Dev. 17: 2765-2776.

Yaffe, M.B., Schutkowski, M., Shen, M., Zhou, X.Z., Stukenberg, P.T., Rahfeld, J.U., Xu, J., Kuang, J., Kirschner, M.W., Fischer, G., et al. 1997. Sequence-specific and phosphorylation-dependent proline isomerization: A potential mitotic regulatory mechanism. Science 278: 1957-1960.

Yamada, T., Yamaguchi, Y., Inukai, N., Okamoto, S., Mura, T., and Handa, H. 2006. P-TEFb-mediated phosphorylation of hSpt5 C-terminal repeats is critical for processive transcription elongation. Mol. Cell 21: 227-237.

Yamaguchi, Y., Takagi, T., Wada, T., Yano, K., Furuya, A., Sugimoto, S., Hasegawa, J., and Handa, H. 1999. NELF, a multisubunit complex containing RD, cooperates with DSIF to repress RNA polymerase II elongation. Cell 97: 41-51.

Zeng, C., Kim, E., Warren, S.L., and Berget, S.M. 1997. Dynamic relocation of transcription and splicing factors dependent upon transcriptional activity. EMBO J. 16: 1401-1412.

Zhang, J. and Corden, J.L. 1991. Phosphorylation causes a conformational change in the carboxyl-terminal domain of the mouse RNA polymerase II largest subunit. J. Biol. Chem. 266: $2297-2302$ 


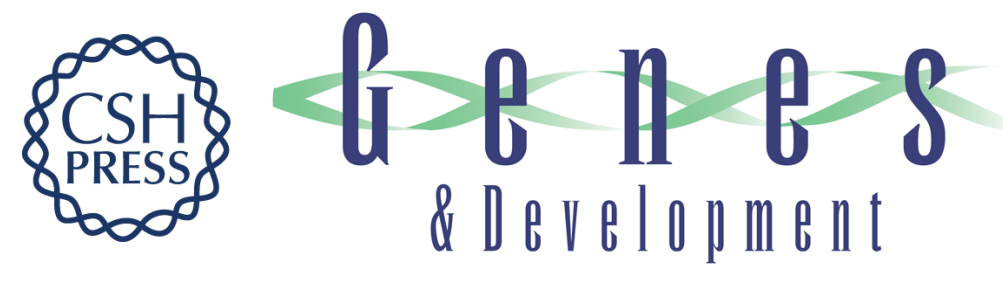

\section{Pin1 modulates RNA polymerase II activity during the transcription cycle}

Yu-Xin Xu and James L. Manley

Genes Dev. 2007, 21:

Access the most recent version at doi:10.1101/gad.1592807

\section{Supplemental http://genesdev.cshlp.org/content/suppl/2007/11/06/21.22.2950.DC1 Material}

References This article cites 54 articles, 33 of which can be accessed free at: http://genesdev.cshlp.org/content/21/22/2950.full.html\#ref-list-1

\section{License}

Email Alerting

Receive free email alerts when new articles cite this article - sign up in the box at the top Service 